\title{
ACEITABILIDADE SENSORIAL E COMPOSIÇÃO FÍSICO-QUÍMICA DE MASSA DE LASANHA SEM GLÚTEN
}

\section{SENSORY ACCEPTABILITY AND PHYSICO-CHEMICAL COMPOSITION OF GLUTEN FREE LASAGNA}

\begin{abstract}
Thaiane Prolo ${ }^{1}$; Marilse Masciel dos Santos ${ }^{1}$; Daiana Novello ${ }^{1}$; Karina Czaikoski ${ }^{1}$; Gabriel Cecchin ${ }^{1}$
${ }^{1}$ Universidade Estadual do Centro-Oeste - UNICENTRO - Guarapuava - Brasil nutridai@ hotmail.com
\end{abstract}

\begin{abstract}
Resumo
Este estudo teve como objetivo desenvolver uma massa de lasanha isenta de glúten, verificando sua aceitabilidade sensorial, bem como sua composição físico-química, comparada a massa padrão. Foram formuladas uma massa padrão -F1- (contendo farinha de trigo) e uma sem glúten -F2(contendo farinha de arroz, fécula de batata, polvilho doce e amido de milho). As duas amostras foram analisadas sensorialmente avaliando-se os atributos aparência, aroma, sabor e textura, bem como a aceitação global e intenção de compra. A composição físico-química avaliou o teor de umidade, proteína, lipídios, carboidratos, calorias e fibra bruta dos produtos. Na análise sensorial observou-se que não houve diferenças estatísticas em relação aos atributos aparência e textura, porém a amostra padrão obteve melhores notas nos atributos aroma e sabor. Verificou-se também, que a aceitação global positiva de ambas as amostras foram maiores que 50\%. A avaliação físicoquímica mostrou que a formulação F1 apresentou maiores quantidades de cinzas, proteínas e fibra bruta, entretanto F2 mostrou maior teor de lipídeos e carboidratos. Foi possível concluir que a massa de lasanha sem glúten pode ser um novo produto alternativo para os pacientes celíacos, sendo mais uma opção alimentar para pessoas com dietas restritas.
\end{abstract}

Palavras-chave: doença celíaca, glúten, cereais, avaliação sensorial.

\section{Introdução}

A doença celíaca (DC), conhecida como espru não tropical, é conceituada pela intolerância permanente ao glúten (SILVA et al., 2006). O glúten consiste no complexo glutamina-gliadina, uma proteína encontrada no trigo (gliadina), centeio (secalina), cevada (hordeína) e aveia (avenina). Estudos caracterizam sua etiologia como hereditária, porém o conjunto de fatores ambientais, genéticos e imunológicos podem desencadear esta patologia (SDEPANIAN et al., 1999; BARBOZA, 2009). As manifestações clínicas da DC são inespecíficas, sendo classificadas em: a) digestivas: má absorção, refluxo gastroesofágico, esofagite, gastrite, diarréia, vômitos; b) cutâneas: eritema, urticária, angioedema; c) respiratórias: renite, asma; d) gerais: irritabilidade, anemia, 
distúrbios do sono, fadiga, letargia, intolerância temporária à lactose (SILVA et al., 2006; BARBOZA, 2009).

Para evitar os sinais e sintomas da patologia, o celíaco não deve consumir nenhum tipo de alimento que contenha glúten como: pães, macarrão, lasanhas, biscoitos, bolos, sopas prontas, dentre outros produtos que tenham sido elaborados com a farinha de trigo, cevada, centeio e aveia. Em estudo realizado por Cassol e Pellegrin (2006) verificou-se que $41 \%$ dos indivíduos avaliados relataram ter dificuldades em seguir a dieta restritiva corretamente devido à indisponibilidade de alimentos no mercado. Em outro estudo realizado por Lee e Newman (2003) observou-se que 67\% dos indivíduos pesquisados apontaram que a dieta restritiva influenciava negativamente na rotina diária e na vida familiar, sendo registrado com maior impacto negativo a dificuldade de jantar fora de casa (86\%), pela indisponibilidade de alimentos. Devido a isto, faz-se necessária a elaboração de novos produtos isentos de glúten, para que a população de celíacos tenha mais opções na sua dieta diária (SDEPANIAN et al., 1999; BARBOZA, 2009). Entretanto, é relevante que esses alimentos apresentem boa aceitabilidade sensorial pelos consumidores, para que sejam incluídos em seu hábito alimentar. Assim, os testes desenvolvidos na prática da análise sensorial são ferramentas relevantes e necessárias para as indústrias (MORAES, 1990; COSTA et al., 2005).

Um dos cereais mais utilizados para a formulação de gêneros alimentícios é o trigo, sendo o principal ingrediente de panificação. Suas proteínas formadoras de glúten conferem viscosidade, resistência, elasticidade e expansão da massa devido à sua capacidade de encapsular, em sua rede protéica, dióxido de carbono produzido durante sua fermentação e cozimento das massas acrescidas de leveduras (STOJCESKA et al., 2007). Já, para o desenvolvimento de novos produtos que não contenham glúten, a farinha de arroz vem se destacando. Quando formulado adequadamente, este ingrediente forma um amido de estrutura semelhante ao do glúten, que é capaz de conferir rigidez e elasticidade à massa (PAGANI et al., 1981; CLERICI e EL-DASH, 2006). Outros ingredientes amplamente utilizados na elaboração de produtos sem glúten são: amido de milho (COLONNA et al., 1992), polvilho ou fécula de mandioca (ABIA, 2000) e, também, a fécula/amido de batata que apresenta boa viscosidade e é recomendada para ser utilizada como espessante em sopas desidratadas e molhos, como agente ligante em linguiças e salsichas, pudins e sobremesas, além de ter baixo custo e alto rendimento (SINGH e SINGH, 2001). Diante do exposto, o objetivo deste trabalho foi elaborar massas de lasanha padrão e sem glúten e verificar a aceitabilidade sensorial, bem como a composição físico-química dos produtos.

\section{Material e Métodos}

\section{Matéria-prima}

Todos os ingredientes utilizados na produção das massas foram adquiridos em um 
supermercado local em Guarapuava-PR. As formulações foram elaboradas no Laboratório de Técnica Dietética, do Departamento de Nutrição, do Campus CEDETEG da UNICENTRO, Guarapuava-PR.

\section{Formulações}

Foram elaboradas duas formulações de massa de lasanha, sendo: F1 padrão (com glúten) e F2 (sem glúten). Os ingredientes utilizados nas formulações foram: farinha de trigo refinada (F1: 71,4\%), farinha de arroz (F2: 30,0\%), farinha de batata (F2: 30,0\%), polvilho doce (F2: 5,0\%), amido de milho (F2: 2,0\%), ovos (F1: 7,1 e F2: 15,0\%), óleo de soja (F1: 2,8 e F2: 6,0\%) e água (F1: 18,6 e F2: 12,0\%).

Primeiramente as farinhas foram misturadas manualmente, sendo acrescentados os demais ingredientes. Em seguida, a formulação foi sovada até formar uma massa lisa e homogênea. Após atingir a consistência desejada, a massa foi aberta manualmente, com auxilio de um rolo doméstico até atingir, aproximadamente, $0,2 \mathrm{~cm}$ de espessura, e em seguida foi cortada em retângulos $(5 \mathrm{~cm}$ de largura por $10 \mathrm{~cm}$ de comprimento). A cocção dos produtos foi realizada em água fervente (100 ${ }^{\circ} \mathrm{C}$ ), por um período de 10 minutos na massa de lasanha padrão (F1) e 20 minutos na massa sem glúten (F2).

\section{Análise Sensorial}

A avaliação sensorial foi realizada no Laboratório de Análise Sensorial do Departamento de Engenharia de Alimentos da UNICENTRO, Guarapuava-PR, em cabines individuais e com iluminação de cor branca. Participaram da pesquisa 50 provadores, não treinados (MACFIE et al., 1989), sendo estudantes e funcionários do Campus CEDETEG da UNICENTRO, de ambos os sexos, com idade entre 18 a 59 anos. Ressalta-se que nenhum julgador relatou ser portador de doença celíaca no momento da avaliação.

Foram avaliados os atributos de aparência, aroma, sabor e textura. As amostras foram analisadas por meio de uma escala hedônica estruturada de 9 pontos, variando de desgostei muitíssimo (nota 1) a gostei muitíssimo (nota 9) (DUTCOSKI, 2011). Foram aplicados também questões de aceitação global e intenção de compra, utilizando-se uma ficha com dois pontos específicos entre "sim" compraria a amostra e "não" não compraria a amostra, como sugerido por Moskowitz (1994). Cada julgador recebeu uma porção de cada amostra (aproximadamente $10 \mathrm{~g}$ ), com temperatura aproximada de $40{ }^{\circ} \mathrm{C}$, em copos plásticos brancos codificados com números de três dígitos, de forma balanceada e casualizada, acompanhada de água para realização do branco entre as amostras. As formulações foram oferecidas aos julgadores de forma monádica sequencial. 
Índice de aceitabilidade (IA)

O cálculo do IA das cinco formulações foi realizado conforme Monteiro (1984), segundo a fórmula: IA $(\%)=A \times 100 / B(A=$ nota média obtida para o produto; $B=$ nota máxima dada ao produto).

\section{Composição físico-química}

A análise da composição físico-química das amostras foi realizada no Laboratório de Análise de Alimentos do Departamento e Engenharia de Alimentos da UNICENTRO, GuarapuavaPR. Determinação da umidade: Foi realizada de acordo com AOAC (2011), que consiste em secagem da amostra a $105{ }^{\circ} \mathrm{C}$ até peso constante. Determinação de cinzas: A porcentagem de cinzas das amostras foi determinada em mufla a $550{ }^{\circ} \mathrm{C}$, conforme metodologia de (AOAC, 2011). Determinação de proteínas: Foi realizada por meio da avaliação do nitrogênio total da amostra, pelo método Kjeldahl determinado ao nível semimicro (AOAC, 2011). Utilizou-se o fator de conversão de nitrogênio para proteína de 6,25. Determinação de lipídios: As amostras foram avaliadas pelo método de determinação a frio proposto por Bligh e Dyer (1959). Determinação de carboidratos: A determinação de carboidratos dos produtos foi realizada por meio de cálculo teórico (por diferença), incluindo fibra bruta, conforme a fórmula: \% Carboidratos $=100-(\%$ umidade + \% proteína $+\%$ lipídios $+\%$ cinzas). Determinação de fibra bruta: A determinação de fibra bruta das amostras foi feita conforme metodologia do Instituto Adolfo Lutz (2008). Determinação do valor calórico total: $\mathrm{O}$ total de calorias (kcal) foi calculado utilizando-se os valores Atwater (ou calor de combustão) para lipídios $(9 \mathrm{kcal} / \mathrm{g})$, proteína $(4,02 \mathrm{kcal} / \mathrm{g})$ e carboidratos (3,87 kcal/g) (ATWATER e WOODS, 1896).

\section{Valor Diário de Referência (VD)}

O VD foi calculado em relação a $100 \mathrm{~g}$ da amostra, com base nos valores médios preconizados para adultos (18 a 59 anos) (DRI, 2005), resultando em: 1944,42 kcal/dia, 250,6 g de carboidratos, 47,6 g de proteínas e 70,6 g de lipídios.

\section{Questões éticas}

Este trabalho foi aprovado pelo Comitê de Ética em Pesquisa da UNICENTRO, Guarapuava, PR, sob protocolo número 324/2011. Entretanto, como fatores de exclusão foram considerados: possuir alergia a algum ingrediente utilizado na elaboração de ambas as massas, possuir doença celíaca, possuir idade maior ou menor do que a faixa de interesse do estudo, não ser aluno ou funcionário do campus em questão e as pessoas que não assinaram o Termo de Consentimento Livre e Esclarecido (TCLE). 


\section{Análises Estatísticas}

A avaliação estatística foi realizada por meio da análise de variância (ANOVA), utilizandose o teste de t de student para comparação de médias e, Qui-quadrado de McNemar em nível de 5\% de significância $(\mathrm{p}<0,05)$, com auxílio do software Statgraphics Plus ${ }^{\circledR}$, versão 5.1.

\section{Resultados e Discussão}

\section{Análise sensorial}

A Tabela 1 apresenta a aceitação sensorial das massas de lasanha com e sem glúten.

Tabela 1 - Médias do teste sensorial afetivo e de intenção de compra realizados para as formulações de massa de lasanha padrão (F1) e sem glúten (F2)

\begin{tabular}{ccc}
\hline Formulações/ & F1 & F2 \\
Atributos & Média $\pm \mathrm{DP}$ & Média $\pm \mathrm{DP}$ \\
\hline Aparência* & $6,74 \pm 1,68 \mathrm{a}$ & $6,18 \pm 1,78 \mathrm{a}$ \\
Aroma* $^{*}$ & $6,90 \pm 1,92 \mathrm{~b}$ \\
Sabor* & $6,90 \pm 1,79 \mathrm{a}$ & $5,86 \pm 1,84 \mathrm{~b}$ \\
Textura* & $7,36 \pm 1,25 \mathrm{a}$ & $6,20 \pm 1,96 \mathrm{a}$ \\
Aceitação global positiva (\%)** & $6,90 \pm 1,68 \mathrm{a}$ & $56,00 \mathrm{~b}$ \\
Intenção de compra positiva (\%)** & $92,00 \mathrm{a}$ & $46,00 \mathrm{~b}$ \\
\hline *Letras diferentes na linha indicam diferença significativa pelo teste de t de student (p<0,05); **Letras diferentes na linha indicam diferença
\end{tabular}

Os atributos aparência e textura não apresentaram diferença significativa entre F1 e F2 ( $\mathrm{p}>0,05$ ). Resultados semelhantes foram obtidos por Lacerda et al. (2009) que elaboraram biscoitos sem glúten com adição de farinha de mandioca e farelo de arroz desengordurado e verificaram uma pontuação (escala hedônica de 9 pontos) de 6,0 e 7,0 em relação à aparência ("gostei ligeiramente" e "gostei regularmente", respectivamente).

Quanto ao aroma e sabor, os provadores atribuíram maiores notas à formulação F1, sendo que a adição dos ingredientes sem glúten diminuiu a aceitação da massa de lasanha. Entretanto, em estudos de Farias (2009) avaliando massa de pizza à base de arroz, foram verificadas maiores pontuações $(6,0$ e 7,0) para o atributo sabor. De forma semelhante aos atributos aroma e sabor, os resultados para aceitação global e intenção de compra, foram mais positivos $(p<0,05)$ na formulação padrão. Dados contraditórios foram verificados por Escouto (2004), que avaliou pães sem glúten, obtendo índices de aceitação global e intenção de compra superiores a 80\%. Entretanto, ressalta-se que os provadores eram portadores de doença celíaca, o que pode ter levado às melhores respostas, uma vez que esta população já está habituada com os ingredientes utilizados nas formulações.

Na Figura 1 verifica-se o índice de aceitabilidade das formulações de massas de lasanha com e sem glúten em relação aos atributos aparência, aroma, sabor e textura. 


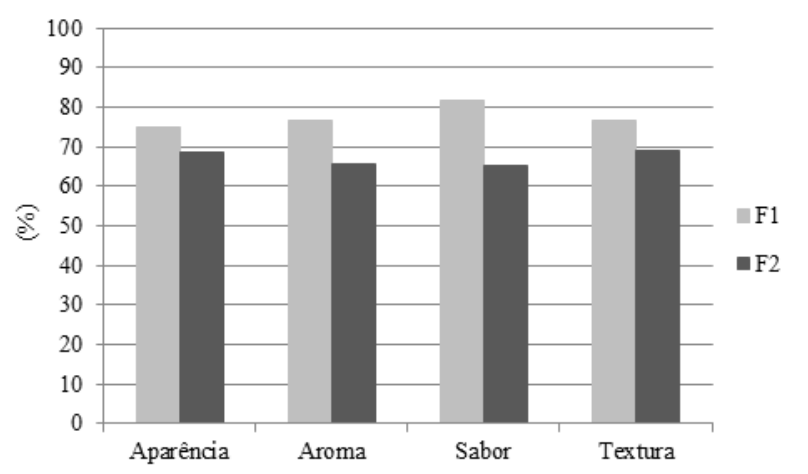

Figura 1- Índice de aceitabilidade das massas de lasanha padrão (F1) e sem glúten (F2), em relação aos atributos avaliados.

Segundo Teixeira et al. (1987) produtos com IA acima de 70\% podem ser classificados com boa aceitação sensorial, assim apenas F1 apresentou os coeficientes conforme o recomendado pelos autores. Na Figura 2 estão apresentas as frequências das notas atribuídas pelos provadores para cada atributo sensorial.
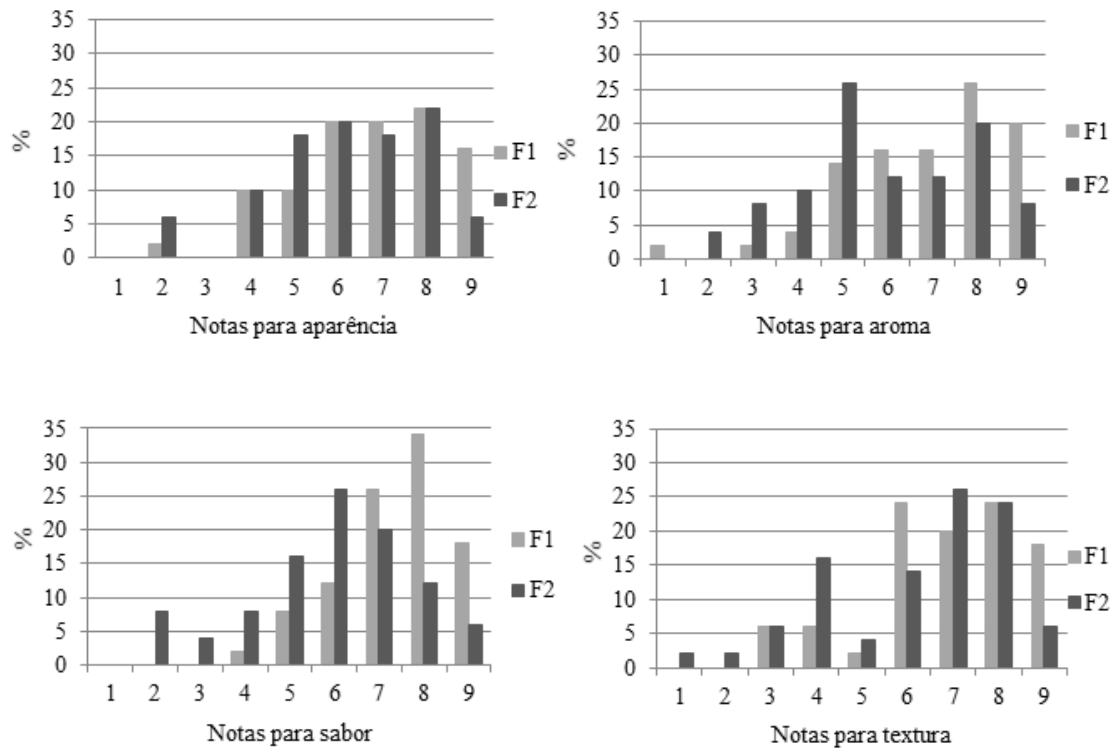

Figura 2 - Distribuição dos provadores pelos valores hedônicos obtidos na avaliação dos atributos aparência, aroma, sabor e textura das massas de lasanha padrão (F1) e sem glúten (F2).

Na Figura 2 pode-se observar que as notas da massa padrão se concentraram entre 7,0 ("gostei moderadamente") e 8,0 ("gostei muito"). Já, a massa sem glúten recebeu notas entre 5,0 e 6,0, o que corresponde respectivamente aos critérios de "nem gostei/nem desgostei" e "gostei ligeiramente". Porém, Mariani (2010) analisando a aceitabilidade de biscoitos formulados com farinha de arroz, farelo de arroz e farinha de soja e o padrão (farinha de trigo), verificou uma aceitação de 4,0 e 5,0 pontos (escala hedônica de 7 pontos) em relação à todos os atributos, o que corresponde ao critério "gostei regularmente". 
É importante ressaltar que as amostras oferecidas aos provadores eram apenas as massas, sem molho ou outro condimento, sendo que o consumo comercial pode ser acrescido de outros ingredientes (molho, carne, queijo, temperos) que podem "mascarar" os atributos da massa, proporcionando uma maior aceitabilidade. Um ponto a se destacar nesta pesquisa é que os testes foram realizados com indivíduos não celíacos e que, normalmente, não tinham o hábito de consumir os ingredientes sem glúten adicionados às formulações. Isso pode explicar as baixas notas obtidas nos atributos de aroma e sabor e para intenção de compra da massa de lasanha sem glúten.

\section{Composição físico-química}

$\mathrm{Na}$ Tabela 2 é possível verificar os resultados da análise físico-química e valores diários recomendados das massas cruas padrão e sem glúten, comparados com um produto referência.

Tabela 2 - Composição físico-química e valores diários recomendados - VD* (porção média de 100 gramas) das massas cruas padrão e sem glúten, comparadas com um produto referência**

\begin{tabular}{|c|c|c|c|c|c|}
\hline \multirow[t]{2}{*}{ Avaliação } & \multicolumn{2}{|l|}{ F1 } & \multicolumn{2}{|l|}{ F2 } & \multirow[t]{2}{*}{ Referência** } \\
\hline & Média $\pm \mathrm{DP}$ & $\mathrm{VD} *$ & Média $\pm D P$ & $\mathrm{VD}^{*}$ & \\
\hline Umidade (\%) & $33,26 \pm 0,04 a$ & - & $33,39 \pm 0,06 a$ & - & 45,00 \\
\hline Cinzas (g. $\left.100 \mathrm{~g}^{-1}\right) * * *$ & $0,63 \pm 0,06 a$ & - & $0,33 \pm 0,04 b$ & - & 1,60 \\
\hline Proteínas $\left(\mathrm{g} .100 \mathrm{~g}^{-1}\right) * * *$ & $7,94 \pm 0,10 \mathrm{a}$ & 16,68 & $2,42 \pm 0,08 b$ & 5,08 & 7,00 \\
\hline Lipídeos (g. $\left.100 \mathrm{~g}^{-1}\right) * * *$ & $4,47 \pm 0,08 b$ & 6,33 & $7,60 \pm 0,10 \mathrm{a}$ & 10,76 & 1,30 \\
\hline Carboidratos $\left(\mathrm{g} .100 \mathrm{~g}^{-1}\right) * * *$ & $53,66 \pm 0,31 b$ & 21,41 & $55,82 \pm 0,49 a$ & 22,27 & 45,10 \\
\hline Valor calórico $\left(\mathrm{kcal} .100 \mathrm{~g}^{-1}\right) * * *$ & $292,16 \pm 3,12 \mathrm{a}$ & 15,02 & $301,11 \pm 1,91 \mathrm{a}$ & 15,49 & 220,00 \\
\hline Fibra bruta $\left(\mathrm{g} .100 \mathrm{~g}^{-1}\right) * * *$ & $2,43 \pm 0,09 a$ & - & $0,08 \pm 0,10 \mathrm{~b}$ & - & 1,60 \\
\hline
\end{tabular}

Letras diferentes na linha indicam diferença significativa pelo teste de t de student ( $<<0,05)$; *VD: nutrientes avaliados pela média da Dietary Reference Intakes (2005), com base numa dieta de 1.944,42 kcal/dia; **Valores comparados com o produto "Lasanha, massa fresca, crua", conforme a Tabela Brasileira de Composição de Alimentos (TACO, 2011); ***Valores calculados em base úmida; ****Cálculo teórico (TACO, 2011); DP: desvio padrão da média; ND: não disponível.

Não houve diferença significativa entre as formulações quanto aos teores de umidade e calorias. Segundo a RDC nº 93 de 31 de outubro de 2000, da Agência Nacional de Vigilância Sanitária (BRASIL, 2000) que fixa o padrão de identidade e qualidade de massas alimentícias, o valor máximo de umidade é de até $35 \%$ para massas frescas, sendo que os valores encontrados para F1 e F2 estão de acordo com esta resolução.

A massa padrão apresentou maior quantidade de cinzas $(\mathrm{p}<0,05)$ que a massa sem glúten, sendo as duas menores que o encontrado no produto referência (TACO, 2011). Maior teor de proteína foi constatado na amostra padrão $(\mathrm{p}<0,05)$. Este fato ocorreu devido à presença de farinha de trigo na formulação padrão, que possui uma alta quantidade de proteína $(9,8 \%)$ em sua composição (TACO, 2011).

O teor de lipídeos totais da massa sem glúten foi significantemente maior do que F1, sendo que as duas formulações apresentaram maiores resultados que o verificado na literatura (TACO, 2011). Este fato pode ser explicado devido à utilização de maior quantidade de óleo e ovos na 
formulação F2, a qual é feita para compensar a função do glúten na massa sem trigo para conferir "liga". Fato semelhante foi relatado por Escouto (2004) avaliando formulações de pão sem glúten, onde se constatou a necessidade de uma maior adição de gordura à massa. Maiores quantidades de lipídios também foram verificados por Mariani (2010), em biscoitos adicionados de farelo de arroz, farinha de arroz e farinha de soja quando comparados ao padrão (farinha de trigo).

$\mathrm{O}$ valor de carboidratos da amostra padrão foi menor $(\mathrm{p}<0,05)$ que em F2, sendo superiores ao produto referência (TACO, 2011). Estes resultados podem ser explicados, pois a farinha de arroz refinada apresenta altos teores de carboidratos e reduzidos em proteínas e lipídeos (FARIAS, 2009).

Houve uma redução significativa de fibra bruta no produto sem glúten (F2) quando comparada a F1, o que se deve, principalmente, a substituição da farinha de trigo, que contém 3,4\% de fibras em sua composição, pela farinha de arroz $(0,2 \%)$, fécula de batata $(0 \%)$, polvilho doce $(0,2 \%)$ e amido de milho $(1,6 \%)$ (TACO, 2011) em F2.

\title{
4. Conclusões
}

A elaboração dos produtos permitiu comprovar que é possível substituir a farinha trigo por outros ingredientes na formulação de massas, obtendo-se, porém, menor aceitação sensorial dos produtos.

Em geral, houve modificação no teor de nutrientes da formulação sem glúten, com aumento no teor de lipídeos e carboidratos e redução de proteínas, cinzas e fibra bruta.

Foi possível verificar que, em média, as amostras com e sem glúten apresentaram maiores conteúdos de nutrientes quando comparados à literatura, estando conforme o recomendado pela legislação vigente.

Destaca-se que devido ao elevado número de pacientes celíacos, é necessário o desenvolvimento e divulgação de novos produtos alimentares, promovendo novas opções alimentares para esse público.

\begin{abstract}
This study aimed to develop a pasta of gluten-free lasagna, verifying its sensory acceptability, as well as its physico-chemical composition compared to standard pasta. A pasta standard-F1-was formulated (containing wheat flour) and one gluten-free -F2- (containing rice flour, potato starch, cassava starch and maize starch). The two samples were analyzed by evaluating the sensory attributes appearance, aroma, taste and texture, as well as the overall acceptance and purchase intent. The physico-chemical composition evaluated the moisture, protein, fat, carbohydrates, calories and crude fiber products. In sensory analysis showed that there were no statistical differences regarding the appearance and texture attributes, but the standard sample obtained top grades in aroma and taste. It was also found that the overall positive acceptance of both samples were greater than 50\%. The physico-chemical evaluation showed that formulation F1 showed higher amounts of ash, protein and crude fiber, however F2 showed higher levels of lipids and
\end{abstract}


carbohydrates. It was concluded that the pasta of gluten-free lasagna can be a new alternative product for celiac patients, food is one more option for people with restricted diets.

Key-words: celiac disease, gluten, cereals, sensory evaluation.

\section{Referências}

AOAC International. Official Methods of Analysis of AOAC International. 18 ed. 4 rev. Gaithersburg: MD, USA, 2011. 1505p.

ASSOCIAÇÃO BRASILEIRA DAS INDÚSTRIAS DE ALIMENTOS (ABIA). Compêndio da legislação de alimentos, atos do Ministério da Saúde: revisão n. 6. São Paulo: ABIA, 2000. 260 p.

ATWATER, W. O.; WOODS, C. D. The chemical composition of American food materials. Farmers' Bulletin, n.28, U.S. Department of Agriculture. Washington, 1896. 46p.

BARBOZA, F. Aspectos clinicos de la alergia alimentaria. Revista Gastrohnup, v. 11, n. 3, p. 167-171, 2009.

BLIGH, E. G.; DYER, W. J. A rapid method of total lipid extraction and purification. Canadian Journal of Biochemistry Physiology, v. 37, n. 8, p. 911-917, 1959. http://dx.doi.org/10.1139/o59-099

BRASIL. Resolução RDC n. 93 de 31 de outubro de 2000. Regulamento Técnico para Fixação de Identidade e Qualidade de Massa Alimentícia. Diário Oficial da União, 01 out. 2000. Disponível em: http://www.anvisa.gov.br/ legis/resol/2000/93_00rdc.htm. Acesso em: 22 jun. 2012.

CASSOL, A. C.; PELlEGRIN, C. P. Perfil dos portadores de doença celíaca associados na ACELBRA-SC. Jornal Sem Glúten + Saúde, v.28, n.7, p.257-265, 2006.

CLERICI, M.T.P.S.; EL-DASH, A.A. Farinha extrusada de arroz como substituto de glúten na produção de pão de arroz. Archivos Latinoamericanos de Nutrición, v. 56, n. 3, p. 288-294, 2006.

COLONNA, P.; LELOUP, V.; BULÉON, A. Limiting factors of starch hydrolysis. European Journal of Clinical Nutrition, v. 46, n. 2, p. 17-32, 1992.

COSTA, E. et al. Caprichos celíacos. Saúde Infantil, v. 2, n. 27, p. 42-46, 2005.

DIETARY REFERENCE INTAKES (DRI). Dietary Reference Intakes for energy, carbohydrate, fiber, fat, fatty acids, cholesterol, protein and amino acids. Washington, D.C.: The National Academies Press, 2005. 1331p.

DUTCOSKI, S. D. Análise sensorial de alimentos. 3 ed. Champagnat: Curitiba, 2011. 426p.

ESCOUTO, L. F. S. Elaboração e Avaliação Sensorial de Pré-Mistura de Massa Para Pão Sem Glúten a Partir de Derivados Energéticos De Mandioca. 2004. Tese (Doutorado em Ciências Agronômicas) - Faculdade de Ciências Agronômicas, Universidade Estadual Paulista, Botucatu, 2004.

FARIAS, A. S. Massas para pizza com restrição de glúten. 2009. 41f. Monografia (Especialização em Turismo) Centro de Excelência em Turismo, Universidade de Brasília, Brasília, 2009.

INSTITUTO ADOLFO LUTZ. Normas analíticas do Instituto Adolfo Lutz: Métodos químicos e físicos para análises de alimentos. v.1. 4 ed. Brasília: IAL, 2008. 1002p.

LACERDA, D. B. C. L.; SOARES, J. M. S.; BASSINELLO, P. Z.; SIQUEIRA, B. S.; KOAKUZU, S. N. Qualidade de biscoitos elaborados com farelo de arroz torrado em substituição à farinha de trigo e fécula de mandioca. Archivos Latinoamericanos de Nutrición, v. 59, n. 2, p. 199-205, 2009.

LEE, A.; NEWMAN, J. M. Celiac diet: Its impact on quality of life. Journal of the American Dietetic Association, v. 103, n. 11, p. 1533-1535, 2003. http://dx.doi.org/10.1016/j.jada.2003.08.027

MACFIE, H. J.; BRATCHELL, N.; GREENHOFF, K.; VALLIS, L. Designs to balance the effect of order of presentation and first-order carry-over effects in hall tests. Journal of Sensory Studies, v. 4, n. 2, p. 129-148, 1989. http://dx.doi.org/10.1111/j.1745-459X.1989.tb00463.x 
MARIANI, M. A. Análise físico-química e sensorial de biscoitos elaborados com farinha de arroz, farelo de arroz e farinha de soja como alternativa para paciente celíaco. Trabalho de Conclusão de Curso, Universidade Federal do Rio Grande do Sul, Porto Alegre, 2010.

MONTEIRO, C. L. B. Técnicas de avaliação sensorial. 2 ed. Curitiba: CEPPA-UFPR, 1984, 101p.

MORAES, M. A. C. Métodos para avaliação sensorial dos alimentos. 7 ed. Campinas: Editora da Unicamp, 1990. 93p.

MOSKOWITZ, H. R. Product optimization approaches and applications. In: MACFIE, H.J.H.; THOMSON, D.M.H. (Ed.) Measurement of food preferences. Glasgow: Blackie Academie \& Professional, 1994. cap. 1, p.97-136.

PAGANI, A.; RESMINI, P.; DALBON, G. Formulazione e produzionedi paste alimentari a partire da materie prime non convenzionali. Técnica Molitoria, v. 32, n. 5, p. 1-24, 1981.

SDEPANIAN, V. L.; MORAIS, M. B.; FAGUNDES-NETO, U. Doença celíaca: a evolução dos conhecimentos desde sua centenária descrição original até os dias atuais. Arquivos de Gastroenterologia, v. 36, n. 4, p. 244-57, 1999.

SIlvA, P. C.; AlmeidA, P. D. V.; AZEVEDO, L. R.; GRÉGIO, A. M. T.; MACHADO, M. A. N.; LIMA, A. A. S. Doença celíaca: revisão. Clínica e Pesquisa em Odontologia, v. 2, n. 5/6, p. 401-406, 2006.

SINGH, J.; SINGH, N. Studies on the morphological, thermal and rheological properties of starch separated from some Indian potato cultivars. Food Chemistry, v. 75, n. 1, p. 67-77, 2001. http://dx.doi.org/10.1016/S0308-8146(01)00189-3

STOJCESKA, V.; BUTLESR, F.; GALLAGHER, E.; KEEHAN, D. A comparison rheological measurement of wheat dough to predict baking behaviour. Journal of the Food Engineering, v. 83, n. 4, p. 475-482, 2007. http://dx.doi.org/10.1016/j.jfoodeng.2007.02.043

TACO. Tabela Brasileira de Composição dos alimentos. UNICAMP. 4. ed. Campinas: NEPA, 2011. 161p.

TEIXEIRA, E.; MEINERT, E.; BARBETTA, P.A. Análise sensorial dos Alimentos. Florianópolis: UFSC, 1987. $180 \mathrm{p}$.

Submetido em 15 dez. 2013, Publicado em 28 dez. 2014. 